\title{
Analysis of the corrective contribution of strong halo-femoral traction in the treatment of severe rigid nonidiopathic scoliosis
}

Hongqi Zhang ${ }^{1,2}$, Guanteng Yang ${ }^{1,2}$, Chaofeng Guo ${ }^{1,2}$, Jinyang Liu ${ }^{1,2}$ and Mingxing Tang ${ }^{1,2^{*}}$ (D)

\begin{abstract}
Introduction: Strong halo-femoral traction has been widely used in the field of severe rigid scoliosis correction. The objective of this study was to analyze the corrective contribution of strong halo-femoral traction in the treatment of severe rigid nonidiopathic scoliosis and discuss its meaning.

Material and methods: A retrospective review was performed for patients with severe rigid nonidiopathic scoliosis who were treated with halo-femoral traction in our center from December 2008 to December 2015. All cases underwent halo-femoral traction for 2 to 4 weeks before a one-stage posterior operation, and the absolute and relative contribution rates of each orthopedic factor (bending, fulcrum, traction, surgery) were analyzed.

Results: A total of 38 patients were included ( 15 males and 23 females), with a mean age of $16.4 \pm 3.73$ years (1022 years) and follow-up of $55.05 \pm 6.63$ months (range 40-68 months). The etiology was congenital in 17 patients, neuromuscular in 14 patients, neurofibromatosis-1 in 3 patients, and Marfan syndrome in 2 patients. Congenital high scapular disease with scoliosis was found in 2 patients. The mean coronal Cobb angle of the major curve was $97.99^{\circ} \pm 11.47^{\circ}$ (range $78^{\circ}-124^{\circ}$ ), with a mean flexibility of $15.68 \% \pm 6.65 \%$. The absolute contribution rate (ACR) of bending was $27.26 \% \pm 10.16 \%$, the ACR of the fulcrum was $10.91 \% \pm 2.50 \%$, the ACR of traction was $32.32 \% \pm$ $11.41 \%$, and the ACR of surgery was $29.50 \% \pm 9.70 \%$. A significant difference in correction was noted between the ACRs of traction and the fulcrum $(P<0.05)$.
\end{abstract}

Discussion: Strong halo-femoral traction plays a relatively significant role in the treatment of severe rigid nonidiopathic scoliosis while decreasing the risk of operation, and it is a safe and effective method for the treatment of severe rigid nonidiopathic scoliosis.

Keywords: Severe rigid nonidiopathic scoliosis, Strong halo-femoral traction, Spinal fusion

\footnotetext{
* Correspondence: tmxspine@163.com

'Department of Spine Surgery and Orthopedics, Xiangya Hospital, Central South University, Changsha, China

${ }^{2}$ National Clinical Research Center for Geriatric Disorders, Xiangya Hospital, Central South University, No. 87, Xiangya Road, Changsha 410008, Hunan, China
}

(c) The Author(s). 2020 Open Access This article is licensed under a Creative Commons Attribution 4.0 International License, which permits use, sharing, adaptation, distribution and reproduction in any medium or format, as long as you give appropriate credit to the original author(s) and the source, provide a link to the Creative Commons licence, and indicate if changes were made. The images or other third party material in this article are included in the article's Creative Commons licence, unless indicated otherwise in a credit line to the material. If material is not included in the article's Creative Commons licence and your intended use is not permitted by statutory regulation or exceeds the permitted use, you will need to obtain permission directly from the copyright holder. To view a copy of this licence, visit http://creativecommons.org/licenses/by/4.0/ The Creative Commons Public Domain Dedication waiver (http://creativecommons.org/publicdomain/zero/1.0/) applies to the data made available in this article, unless otherwise stated in a credit line to the data. 


\section{Introduction}

Nonidiopathic scoliosis includes congenital scoliosis, neuromuscular scoliosis, neurofibromatosis-1, and Marfan syndrome, which usually presents as a known pathogeny with an early onset and rapid progression, leading to complex spinal deformities. Severe rigid nonidiopathic scoliosis is often associated with neural axis malformations, pulmonary dysfunction, and malnutrition, thus increasing the potential risk of a correction [1-4]. To decrease the risk of a correction, preoperational traction is applied in the treatment of nonidiopathic scoliosis.

Current methods of traction include halo-pelvic traction (HPT), halo-gravity traction (HGT), and halofemoral traction (HFT). HPT provides a consistent force to the spine, but it causes severe trauma while placing the pins and is inconvenient for daily nursing and sleep. HGT is the most widely used traction method in clinical practice. During a long period of traction, the height of the thoracic spine and rib cage gradually lengthened, and the volume of the lungs also enlarged. Although patients have a good tolerance in HGT, since the procedure does not need patients to be absolutely lying in bed, the traction force of HGT is limited. In recent years, an increasing number of studies have focused on the treatment of complex spinal deformities via HFT preoperatively [5]. HFT can offer more powerful traction from both caudal and cephalic ends than the HGT. The simultaneous traction weight gradually enlarges the intervertebral space, resulting in alleviation of the angle of the main and secondary curve, thus improving the compliance of the spine and pulmonary function, which in return downsizes the deformity and helps avoid severe complications such as spinal cord injury. Additionally, preoperative improvement of the curve is proven to be beneficial for corrective surgery outcomes [4, 6-8].

However, to date, there are few reports on the treatment of severe rigid nonidiopathic scoliosis assisted by preoperative HFT. Hence, by reviewing a series of patients in our center and evaluating each parameter related to deformity correction, we aimed to assess the contribution of strong HFT to correction and the clinical value of HFT combined with one-stage posterior surgery in the treatment of severe rigid nonidiopathic scoliosis.

\section{Material and methods}

\section{Clinical information}

A retrospective review was performed for patients with severe rigid nonidiopathic scoliosis who were treated in our center between December 2008 and December 2015. All patients underwent physical and imaging examinations (X-ray, CT, MRI). All patients are reviewed inperson. The indications for preoperative HFT combined with one-stage posterior instrumentation and fusion were based on (1) a coronal Cobb angle of the major curve $>70^{\circ}$ and bending flexibility $<30 \%$, (2) no history of previous spinal surgery, (3) no preoperative neurologic symptoms, (4) a minimum of 2 years of follow-up, and (5) complete medical records and image data. The exclusion criteria were (1) had a history of spine surgery, (2) received anterior release, and (3) receiving three column osteotomies.

\section{Radiographic analysis}

Standing long-cassette anteroposterior (AP) and lateral radiographs of the whole spine were taken at each point (before traction, after the operation and at the final follow-up). Supine long-cassette anteroposterior (AP) radiographs were taken each week after traction. Coronal and sagittal Cobb angles were measured on standing AP films, side bending films, and fulcrum-pushing films at each point (Additional file 1). The absolute contribution rate (ACR) of every corrective element was calculated by the following formula: MC: Major curve

Bending $\mathrm{ACR}(\%)=$ (preoperative $\mathrm{MC}$ Cobb angel - Cobb angle on bending film) /(preoperative MC Cobb angel - postoperative MC Cobb angle)

Fulcrum ACR $(\%)=($ Cobb angle on bending film - Cobb angle on fulcrum film $)$ /(preoperative MC Cobb angel - postoperative MC Cobb angle)

Traction ACR $(\%)=($ Cobb angle on fulcrum film - Cobb angle after traction $)$ /(preoperative MC Cobb angel - postoperative MC Cobb angle)

Surgery $\operatorname{ACR}(\%)=($ cobb angle after traction - cobb angle after surgery $)$ /(preoperative MC cobb angel - postoperative MC cobb angle)

The relative contribution rate (RCR) of every corrective element was calculated by the following formula:

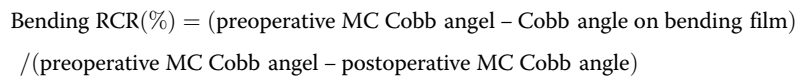

\section{Traction protocol}

Traction was started with a weight of $2 \mathrm{~kg}$ and gradually increased at a rate of 1 to $2 \mathrm{~kg}$ per day if the patients showed sufficient tolerance. According to the patients' condition, the maximum traction weight was adjusted to 
Table 1 Demographic of study populations

\begin{tabular}{ll}
\hline General information & cases $\boldsymbol{n}=\mathbf{3 8}$ \\
\hline Gender & $15(60.52 \%)$ \\
Male & $23(69.56 \%)$ \\
Female & \\
Diagnosis & $17(44.73 \%)$ \\
Congenital scoliosis & $14(36.84 \%)$ \\
Neuromuscular scoliosis & $3(7.89 \%)$ \\
Neurofibromatosis-1 scoliosis & $2(5.26 \%)$ \\
Marfan syndrome with scoliosis & $2(5.26 \%)$ \\
Congenital high Scapular disease with scoliosis & \\
Traction related complication & $1(2.63 \%)$ \\
Brachial plexus palsy & $1(2.63 \%)$ \\
Pin tract infection & $1(2.63 \%)$ \\
Deep vein thrombosis & $1(2.63 \%)$ \\
Femoral nerve palsy & $2(5.26 \%)$ \\
Rigid knee/hip & \\
Patient resides & $27(71.05 \%)$ \\
Rural & $11(28.94 \%)$ \\
City &
\end{tabular}

$33-50 \%$ of the whole-body weight. Traction was maintained for a minimum of $18 \mathrm{~h}$ per day with the traction weight was unchanged at night if the patients did not complain of discomfort. During traction, the patient's neurological status was frequently checked. If the Babinski sign, paresthesia, or any neurological compromise was noted, the weight was reduced immediately.

The active or passive joint exercise was performed to avoid rigid joints during the interval of traction, and pulmonary function training was also performed during traction. The length of the traction period was mainly determined by the radiographic evidence of curve improvement on weekly radiographs.

\section{Posterior instrumentation}

Surgery was performed with halo-femoral traction intraoperatively. The patients were positioned prone maintaining halo-femoral traction with $1 / 3$ of their body weight. All 38 patients were treated by hybrid constructs with screws and/or hooks. During the surgery, continuous neuro-monitorization was performed, and a wakeup test was performed after the final correction. Once the posterior surgery was performed, the halo-femoral apparatus was removed.

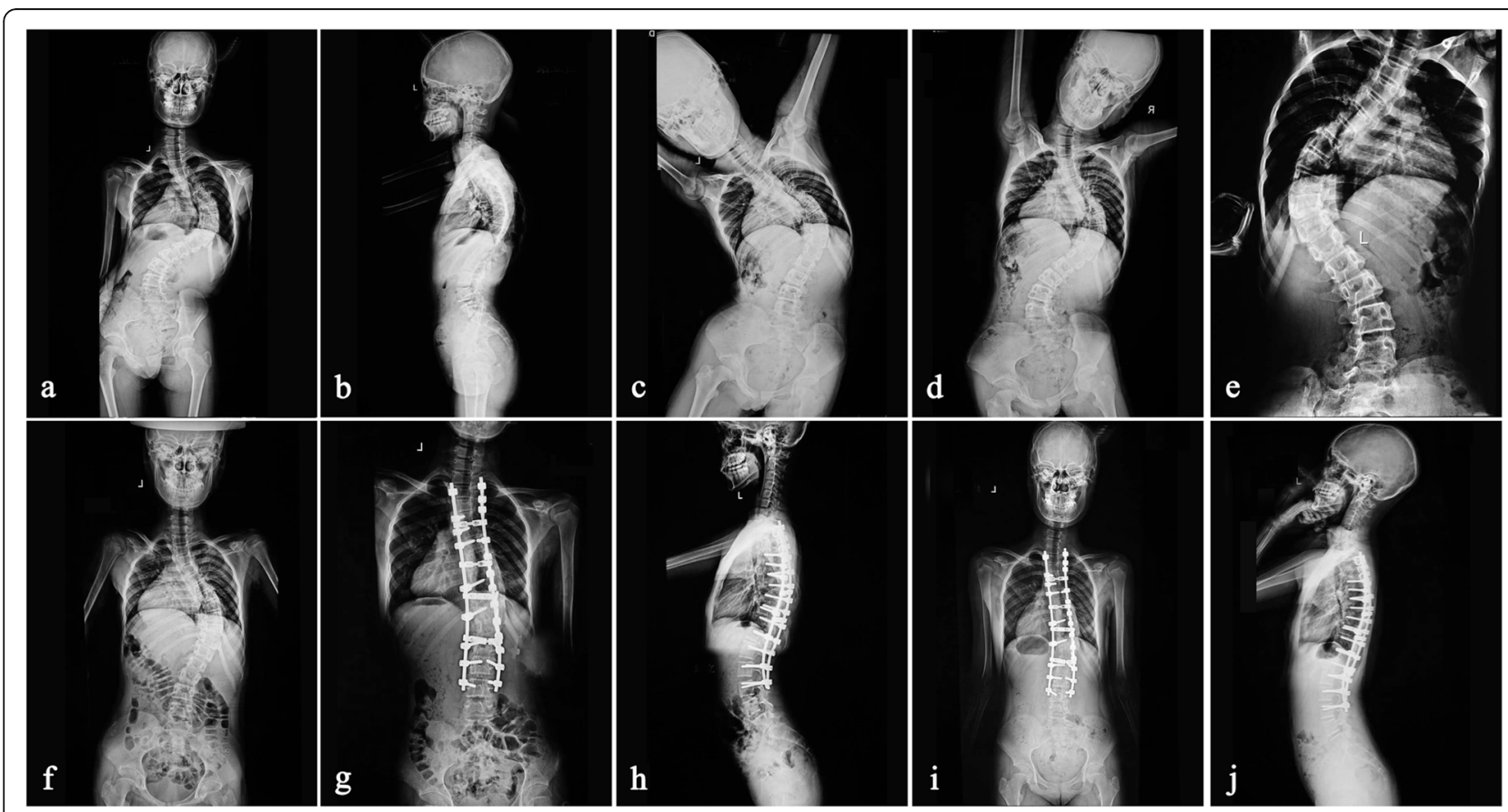

Fig. 1 A 15-year-old female patient with Marfan syndrome had a scoliosis of $92^{\circ}$ (a) and a kyphosis of $76^{\circ}$ (b). Major coronal curve decreased to $80^{\circ}$ (d) at side bending radiograph and then decreased to $72^{\circ}$ (e) at fulcrum radiograph. After a 3-week traction, scoliosis was corrected to $58^{\circ}(\mathbf{f})$ Postoperative standing radiograph demonstrated scoliosis was corrected to $24^{\circ}(\mathbf{g})$, and kyphosis to $18^{\circ}(\mathbf{h})$, and the 2-year follow-up shows the scoliosis was $26^{\circ}(\mathbf{i})$, and kyphosis to $20^{\circ}$ (j) 


\section{Postoperative procedure}

The drain was usually removed when the drainage flow was less than $30 \mathrm{ml} / 24 \mathrm{~h}$. Patients were allowed to ambulate with a brace after remaining supine for 14 days postoperatively. The braces were continuously used for 6 to 8 months postoperatively. For better recovery, muscle strength training such as the leg raising straight sport and swimming is recommended.

\section{Evaluation of index and statistical analysis}

The data were analyzed using SPSS (version 25.0, SPSS Inc.). Paired $t$ tests were used to compare parameters at the preoperative, postoperative, and final follow-up stages. A $p$ value $<0.05$ indicated a statistically significant difference.

\section{Results}

\section{Patient characteristics}

A total of 38 patients were included (15 males and 23 females, mean age $16.4 \pm 3.73$ years, range $10-22$ years) with a mean follow-up period of $55.05 \pm 6.63$ months (range 40-68 months). 27 patients were living in rural area while the other 11 patients were living in city. The etiology was congenital in 17 patients, neuromuscular in 14 patients, neurofibromatosis- 1 in 3 patients, and Marfan syndrome in 2 patients. Congenital high scapular disease with scoliosis was found in 2 patients (Table 1). The mean operation time was $4.83 \pm 0.79 \mathrm{~h}$, and the average days with maximum weight traction were 18.26 \pm 2.43 days (14-23 days). The average maximum traction weight was $18.23 \mathrm{~kg} \pm 1.99 \mathrm{~kg}$, which was equal to $46.46 .2 \% \pm 1.99 \%$ (range $36-54.9 \%$ ) of the patients' total body weight.

\section{Radiographic analysis}

The average preoperative major curve magnitude was $97.99^{\circ} \pm 11.47^{\circ}$ (range $78-124^{\circ}$ ), which decreased to $83.00^{\circ} \pm 14.0^{\circ}$ (range $58-106^{\circ}$ ) on side bending and then reduced to $76.97^{\circ} \pm 14.31^{\circ}$ (range $50-100^{\circ}$ ) on the fulcrum film. The major curve averaged $59.53^{\circ} \pm 12.02^{\circ}$ (range $39-82^{\circ}$ ) at the end of the halo-femoral traction treatment and then improved to $44.42^{\circ} \pm 12.09^{\circ}$ (range $26-72^{\circ}$ ) after posterior corrective surgery. The mean Cobb angle at final follow-up was $46.73^{\circ} \pm 12.46^{\circ}$ (range $\left.28-79^{\circ}\right)$. The average preoperative kyphosis angle was $66.29^{\circ} \pm 13.51^{\circ}$ (range $51-107^{\circ}$ ), which decreased to $31.71^{\circ} \pm 7.52^{\circ}$ (range $21-50^{\circ}$ ) postoperatively and $33.76^{\circ}$ $\pm 7.68^{\circ}$ (range $22-52^{\circ}$ ) at the final follow-up (Fig. 1). The average preoperative $\mathrm{C} 7$ plumb line to center sacral vertical line (C7-CSVL) was $12.5 \pm 3.8 \mathrm{~mm}$, which decreased to $6.94 \pm 4.6 \mathrm{~mm}$ postoperatively and $7.26 \pm$ $5.8 \mathrm{~mm}$ at the final follow-up. The average preoperative sagittal vertebrae axis (SVA) was $28.4 \pm 15.8 \mathrm{~mm}$, which
Table 2 Radiographic data of study populations

\begin{tabular}{ll}
\hline General information & \\
\hline The cobb angel of the major curve & \\
AP film & $97.99^{\circ} \pm 11.47^{\circ}$ \\
Bending film & $83.00^{\circ} \pm 14.0^{\circ}$ \\
Fulcrum film & $76.97^{\circ} \pm 14.31^{\circ}$ \\
After traction film & $59.53^{\circ} \pm 12.02^{\circ}$ \\
Postoperation film & $44.42^{\circ} \pm 12.09^{\circ}$ \\
Final follow-up film & $46.73^{\circ} \pm 12.46^{\circ}$ \\
The kyphosis angle of the major curve & \\
Preoperation film & $66.29^{\circ} \pm 13.51^{\circ}$ \\
Postoperation film & $31.71^{\circ} \pm 7.52^{\circ}$ \\
Final follow-up film & $33.76^{\circ} \pm 7.68^{\circ}$ \\
C7-CSVL & \\
Preoperation & $12.5 \pm 3.8 \mathrm{~mm}$ \\
Postoperation & $6.94 \pm 4.6 \mathrm{~mm}$ \\
Final follow-up & $7.26 \pm 5.8 \mathrm{~mm}$ \\
SVA & \\
Preoperation & $28.4 \pm 15.8 \mathrm{~mm}$ \\
Postoperation & $21.2 \pm 9.6 \mathrm{~mm}$ \\
Final follow-up & $23.4 \pm 10.5 \mathrm{~mm}$ \\
\hline
\end{tabular}

decreased to $21.2 \pm 9.6 \mathrm{~mm}$ postoperatively and $23.4 \pm$ $10.5 \mathrm{~mm}$ at the final follow-up (Table 2).

\section{Correction rate-related factors}

The absolute contribution of bending to correction was $27.26 \% \pm 10.16 \%$, the absolute contribution of the fulcrum to correction was $10.91 \% \pm 2.50 \%$, the absolute contribution of traction to correction was $32.32 \% \pm 11.41 \%$, and the absolute contribution of surgery to correction was $29.50 \% \pm 9.70 \%$. A significant difference in correction was noted between the absolute contribution rate of traction and the absolute contribution rate of the fulcrum $(p<$ 0.05), and there was no significant difference when comparing the absolute contribution rate of traction to that of bending or surgery $(p>0.05)$ (Table 3$)$.

The relative contribution of bending to correction was $27.26 \% \pm 10.16 \%$, the relative contribution of the fulcrum to correction was $38.17 \% \pm 11.57 \%$, and the relative contribution of traction to correction was $74.05 \% \pm$ $14.77 \%$. There was a significant difference when comparing the relative contribution rate of traction to the bending or fulcrum relative contribution rates $(p<0.05)$ (Table 3).

\section{Complications}

During traction, 1 patient experienced brachial plexus palsy, and 1 patient experienced femoral nerve palsy. The symptoms disappeared after the removal of the 
Table 3 Absolute and relative contribution rate of each factor

\begin{tabular}{lllll}
\hline & Bending contribution rate & Fulcrum contribution rate & Traction contribution rate & Surgery contribution rate \\
\hline Absolute & $27.26 \% \pm 10.16 \%$ & $10.91 \% \pm 2.50 \%$ & $32.32 \% \pm 11.41 \%^{*}$ & $29.50 \% \pm 9.70 \%$ \\
Relative & $27.26 \% \pm 10.16 \%$ & $38.17 \% \pm 11.57 \%$ & $74.05 \% \pm 14.77 \%^{\#^{*}}$ & - \\
\hline
\end{tabular}

${ }^{\#}$ Compared with bending contribution rate, $P<0.05$

* Compared with fulcrum contribution rate, $P<0.05$

increased weight. One patient suffered from deep vein thrombosis (DVT), and the patient then underwent inferior vena cava filter placement. A pin infection occurred in 1 patient and was controlled by debridement. Two patients developed a rigid knee/hip due to fear of moving the knee/hip. The total incidence of traction complications was $15.8 \%$ (Table 1 ).

\section{Discussion}

HGT has been reported to successfully assist in the management of spinal deformities [9-11]. However, due to the limited traction weight, the efficiency of treating severe rigid scoliosis is debated. Yang et al. [12] systematically reviewed a total of 351 severe spinal deformity patients treated with HGT preoperatively, and the patients did not have better correction postoperatively. Koller et al. [13] reported that HGT did not significantly improve severe curves without prior anterior or posterior surgical release. Sponseller et al. [14] found that HGT did not increase the main coronal curve or sagittal plane correction in a multicenter, retrospective, nonrandomized comparison study.

Compared to HGT, which has a limited traction weight, HFT can offer stronger and simultaneous traction forces $[15,16]$. In our study, the mean preoperative major curve was $97.99^{\circ} \pm 11.47^{\circ}$, with a mean flexibility of $15.68 \% \pm 6.65 \%$, and it had only a $6.23 \% \pm 1.79 \%$ improvement on the fulcrum film; however, after a mean $18.15 \pm 2.01 \mathrm{~kg}(46.46 \% \pm 5.36 \%$ of body weight $)$ maximum traction weight for $18.26 \pm 2.43$ days, the average correction rate added $17.83 \% \pm 5.41 \%$, reaching a total of $39.74 \% \pm 6.22 \%$ at the end of HFT. Similarly, Wang et al. [7] reported 21 cases with extremely severe rigid scoliosis treated by HFT before posterior vertebral column resection. The mean preoperative major curve was $153^{\circ}$, and after 4 weeks of traction, the mean decrease in Cobb angle achieved a $33.7 \%$ correction of scoliosis. The advantages of strong HFT could be three-fold: first, strong HFT can offer patients more effective traction time, and traction effects tend to be better, especially when applied during sleep at night to weak muscles. Thus, through continuous heavy traction, paravertebral soft tissue and intervertebral space not only in the area of the major curve but also in the second curve can be released. Second, severe rigid nonidiopathic scoliosis is often associated with neural axis malformations. The gradually increased corrective force contribution helps the surgeon assess the tolerance of the spinal cord, which helps to achieve adequate reduction and optimum balance. Moreover, during the traction period, patients can improve their pulmonary function and malnutrition states, thus increasing their tolerance of the operation and reducing hospital stays and costs.

Another advantage of HFT is that the patients will maintain HFT during surgery, and intraoperative halofemoral traction leads to apical vertebral de-rotation. This de-rotation of the spine facilitates surgical exposure and screw rod insertion and limits the force on implants $[17,18]$. In the present study, we also performed intraoperative HFT during the posterior surgery, and the Cobb angle improved to $42.56^{\circ} \pm 11.63^{\circ}$ after posterior corrective surgery. The average correction rate obtained was $59.5 \% \pm 8.5 \%$ without any postoperative neurological complications.

In our study, the absolute contribution rate of bending was $27.26 \% \pm 10.16 \%$, the absolute contribution rate of the fulcrum was $10.91 \% \pm 2.50 \%$, the absolute contribution rate of traction was $32.32 \% \pm 11.41 \%$, and the absolute contribution rate of surgery was $29.50 \% \pm 9.70 \%$. In terms of the first-level corrective force, the Cobb angle improvement of bending is relatively easy to obtain, while for the second-level corrective force, i.e., that of the fulcrum, the Cobb angle improvement is relatively demanding to obtain because only with a vertical push force at the coronal parietal region can this measurement be effective. Traction, as the third-level corrective force, is difficult to obtain. Our results show that both the second level and the third level of corrective force were obtained after an average of $18.26 \pm 2.43$ days of HFT. The average correction after traction was an average of $39.74 \% \pm 6.22 \%$, which was a significant improvement compared with the correction obtained from the side fulcrum film in our study $(p<0.05)$. This statistically significant difference confirms the efficacy of the HFT technique. The HFT applied in our research is effective for the correction of severe rigid nonidiopathic scoliosis, further correcting spinal deformity, which remarkably decreases large Cobb angles, greatly simplifies intraoperative operation difficulty, reduces surgical trauma, and reduces the overall risk of patients.

The complications related to HFT included pin loosening, superficial and deep pin tract infections, brain abscess, cerebral nerve damage, and brachial plexus injury. In our study, 1 patient suffered from superficial pin tract 
infections, and after debridement and anti-infection treatment, the patient recovered. One patient suffered from DVT and underwent inferior vena cava filter placement. Pin infection occurred in 1 patient and was controlled by debridement. Two patients developed a rigid knee/hip due to fear of moving the knee/hip, and the symptoms subsided after surgery. Traction with excessive weight, a long duration or a rapid increase in the load may lead to neurological complications. However, most of the neurologic injuries $(92-100 \%)$ caused by preoperative traction were transient [19]. In our study, 1 patient had brachial plexus palsy, and 1 patient had femoral nerve palsy. Symptoms disappeared after removal of the increased weight. No patient developed neurological deficits when the surgical correction was finished. We believe that this is a benefit of preoperative traction, as the surgeons obtained an accurate assessment of the spinal cord status and then used this knowledge to soundly control cord tension. Meanwhile, it also explains why for extremely severe patients, we need preoperative traction instead of intraoperative traction alone. From the perspective of cord safety, we believe preoperative traction is far more relevant than intraoperative traction for this type of patient.

The limitations of this study were as follows: in this study, we focus on the improvement of coronal Cobb angle, in order to assess the contribution rate of strong HFT in the treatment of severe rigid non-idiopathic scoliosis. As for aspects including sagittal improvement and function recovery, further research is needed. Besides, the number of cases remains to be further accumulated.

\section{Conclusion}

Strong halo-femoral traction plays a relatively significant role in the treatment of severe rigid nonidiopathic scoliosis while decreasing the risk of operation, and it is a safe and effective method for the treatment of severe rigid nonidiopathic scoliosis.

\section{Supplementary Information}

The online version contains supplementary material available at https://doi. org/10.1186/s13018-020-02093-8.

Additional file 1: Fig. S1. Diagrammatic explanation to the terms used for the radiographic analysis.

\section{Abbreviations}

ACR: Absolute contribution rate; HFT: Halo-femoral traction; HGT: Halo-gravity traction; AP: Anteroposterior; MC: Major curve; RCR: Relative contribution rate; DVT: Deep vein thrombosis

\section{Acknowledgements}

The authors thank all the staff of the Department of Spine Surgery, Xiangya Hospital, Central South University, for their dedicated assistance in patient sample collection.

\section{Authors' contributions}

$\mathrm{HZ}$ and MT designed the study. JL and CG performed the data collection, statistical analysis, and data interpretation. YG contributed to the manuscript writing. YG and HZ contributed to the patient enrollment and follow-up. The authors read and approved the final manuscript.

\section{Funding}

This work was supported by the National Natural Science Foundation of China (No. 81772298), the role of which was the design of the study, and the National Natural Science Foundation of Hunan Province, China (No. 2019JJ40523 and No.2018JJ6060), the role of which included the purchase of reagents and English editing.

\section{Availability of data and materials}

All data generated or analyzed during this study are included in this published article.

\section{Ethics approval and consent to participate}

This study was conducted adhering to the principles of the Declaration of Helsinki II and approved by the medical ethics committee of Xiangya Hospital, Central South University (ethical code: 201703358). Written informed consent was obtained from all the study participants or their parents or guardians.

\section{Consent for publication}

Not applicable.

Received: 14 June 2020 Accepted: 11 November 2020

Published online: 30 November 2020

\section{References}

1. Zhang Y, Xie J, Wang Y, Bi N, Li T, Zhang J, Zhao Z, Ou H, Liu S. Intraspinal neural axis abnormalities in severe spinal deformity: a 10-year MRI review. Eur Spine J. 2019;28:421-5.

2. Zhao H, Hu Z, Zhao D, Wang F, Zhong R, Liang Y. The valuation of concaveside thoracoplasty on the treatment of extremely severe scoliosis with severe pulmonary dysfunction on the base of halo-pelvic traction. Medicine (Baltimore). 2019;98:e17073.

3. Zhang W, Sha S, Xu L, Liu Z, Qiu Y, Zhu Z. The prevalence of intraspinal anomalies in infantile and juvenile patients with "presumed idiopathic" scoliosis: a MRI-based analysis of 504 patients. BMC Musculoskelet Disord. 2016;17:189.

4. Zhang HQ, Deng A, Liu SH, Wang YX, Alonge E. Posterior-only surgical correction with heavy halo-femoral traction for the treatment of severe and rigid congenital scoliosis associated with tethered spinal cord and type II split cord malformation. World Neurosurg. 2020;139:e151-8.

5. Zhang H, Liu S, Guo C, Chen L, Wang Y, Zhao D, Chen J. Posterior surgery assisted by halo ring traction for the treatment of severe rigid nonangular cervical kyphosis. Orthopedics. 2010;33:4.

6. Qiu Y, Liu Z, Zhu F, Wang B, Yu Y, Zhu Z, Qian B, Ma W. Comparison of effectiveness of halo-femoral traction after anterior spinal release in severe idiopathic and congenital scoliosis: a retrospective study. J Orthop Surg Res. 2007:2:23

7. Wang Y, Xie J, Zhao Z, Li T, Zhang Y, Bi N, Shi Z, Cai Y, Zhang Y. Preoperative short-term traction prior to posterior vertebral column resection: procedure and role. Eur Spine J. 2016;25:687-97.

8. Zhang HO Wang YX, Guo CF, Tang MX, Chen LO, Liu SH, Wang YF, Chen J. Posterior-only surgery with strong halo-femoral traction for the treatment of adolescent idiopathic scoliotic curves more than 100 degrees. Int Orthop. 2011;35:1037-42.

9. Xu E, Gao R, Jiang H, Lin T, Shao W, Zhou X. Combined halo gravity traction and dual growing rod technique for the treatment of early onset dystrophic scoliosis in neurofibromatosis type 1. World Neurosurg. 2019;126:e173-e180.

10. Watanabe K, Lenke LG, Bridwell KH, Kim YJ, Hensley M, Koester L. Efficacy of perioperative halo-gravity traction for treatment of severe scoliosis $(>/=100$ degrees ). J Orthop Sci. 2010;15:720-30.

11. Mejabi JO, Sergeenko OM, Ryabykh SO. Correction using halo gravity traction for severe rigid neuromuscular scoliosis: a report of three cases. Malays Orthop J. 2019;13:49-53. 
12. Yang C, Wang H, Zheng Z, Zhang Z, Wang J, Liu H, Kim YJ, Cho S. Halogravity traction in the treatment of severe spinal deformity: a systematic review and meta-analysis. Eur Spine J. 2017;26:1810-6.

13. Koller H, Zenner J, Gajic V, Meier O, Ferraris L, Hitzl W. The impact of halogravity traction on curve rigidity and pulmonary function in the treatment of severe and rigid scoliosis and kyphoscoliosis: a clinical study and narrative review of the literature. Eur Spine J. 2012;21:514-29.

14. Sponseller PD, Takenaga RK, Newton P, Boachie O, Flynn J, Letko L, Betz R, Bridwell K, Gupta M, Marks M, Bastrom T. The use of traction in the treatment of severe spinal deformity. Spine (Phila Pa 1976). 2008;33:2305-9.

15. Hong-qi Z, Gao Q-I, Lei G, Jian-huang W, Jin-yang L, Chao-feng G, Shao-hua L, Shi-jin L, Jin-song LI, Xin-hua Y, Feng L. Strong halo-femoral traction with wide posterior spinal release and three dimensional spinal correction for the treatment of severe adolescent idiopathic scoliosis. Chin Med J (Engl). 2012;125(7):1297-302

16. Zhang HQ, Deng A, Tang MX, Liu SH, Wang YX, Gao QL. Posterior-only surgical correction with heavy halo-femoral traction for the treatment of rigid congenital scoliosis associated with split cord malformation. BMC Musculoskelet Disord. 2020;21:98.

17. Kulkarni AG, Shah SP. Intraoperative skull-femoral (skeletal) traction in surgical correction of severe scoliosis (>80 degrees) in adult neglected scoliosis. Spine (Phila Pa 1976). 2013;38:659-64.

18. Hamzaoglu A, Ozturk C, Aydogan M, Tezer M, Aksu N, Bruno MB. Posterior only pedicle screw instrumentation with intraoperative halo-femoral traction in the surgical treatment of severe scoliosis (>100 degrees). Spine (Phila Pa 1976). 2008:33:979-83.

19. Limpaphayom N, Skaggs DL, McComb G, Krieger M, Tolo VT. Complications of halo use in children. Spine (Phila Pa 1976). 2009;34:779-84.

\section{Publisher's Note}

Springer Nature remains neutral with regard to jurisdictional claims in published maps and institutional affiliations.

Ready to submit your research? Choose BMC and benefit from:

- fast, convenient online submission

- thorough peer review by experienced researchers in your field

- rapid publication on acceptance

- support for research data, including large and complex data types

- gold Open Access which fosters wider collaboration and increased citations

- maximum visibility for your research: over $100 \mathrm{M}$ website views per year

At $\mathrm{BMC}$, research is always in progress.

Learn more biomedcentral.com/submissions 